\title{
Vitamin a deficiency as a global public health threat: a concern in nutritional victimization
}

\section{Opinion}

Vitamin A deficiency is on the helm of great public health panic across the globe, especially in developing and poor countries. Vitamin A deficiency disease night blindness by name affects about 2.5 million preschoolers and 9.8 million pregnant women as corresponding to $0.9 \%$ and $7.8 \%$ of the population at risk of vitamin A deficiency diseases respectively and about one-third of the world preschoolers are estimated in vitamin A deficiency sufferers in South East Asia and in Africa. ${ }^{1,2}$

The premier etiology to form vitamin A deficiency is prolonged vitamin A lacking diet consumption, resulting in failure to sustain the physiological requirement in infancy, childhood, adulthood, pregnancy, lactation and geriatric., ${ }^{3,4}$ There are different active and passive risk factors in this connection like food taboos, gender bias, genetic codes, poor socioeconomic condition, measles, respiratory infection, malnutrition, agricultural production, inadequate government policy have been endorsed in vitamin A deficiency causation $^{5-9}$ and the vitamin A deficiency prevalence is diagnosed using clinical or biochemical parameters. ${ }^{1}$ This condition can cause xeropthalmia, anemia and liable to lead infection and risk of growth retardation and death in severe condition. ${ }^{1,10,11}$

It is a dilemma that xerophthalmia has not been controlled despite taking different measures in different countries in the world. ${ }^{12,13}$ It is high time to organize $1 / \mathrm{n}$ nutrition counseling ${ }^{14}$ across different topographic sites in the earth to resist nutritional victitogenesis ${ }^{15,16}$ relied on vitamin A deficiency aiming to meet the true occurrence of malnutrition rebuking movement by $2020 .{ }^{17,18}$

\section{Acknowledgements}

None.

\section{Conflict of interest}

Author declares that there is no conflict of interest.

\section{References}

1. World Health Organization (WH0). Global prevalence of vitamin A deficiency in populations at risk 1995-2005. WHO Global Database on Vitamin A Deficiency. Geneva; 2009.

2. Hakim MA, Kamruzzaman M. Nutritional Status of Preschoolers in Four Selected Fisher Communities. American Journal of Life Sciences. 2015;3(4):332-336.

3. Sing V, West KP. Vitamin A deficiency and Xeropthalmia among school aged children in South eastern Asia. Eur $J$ Clin Nutr. 2004;58(10):1342-1349.

4. Christin P. Recommendations for indicators: Night blindness during pregnancy- a simple tool to assess vitamin A deficiency in population. $J$ Nutr. 2002;132(9 Suppl):2884S-28848S.

\author{
Volume 4 Issue 5 - 2016
}

\author{
Abdul Hakim \\ Mawlana Bhashani Science and Technology University, \\ Bangladesh
}

Correspondence: Abdul Hakim, School of Food Technology and Nutritional Science, Mawlana Bhashani Science and Technology University, Tangail, Bangladesh, Email info.hakim.bd@gmail.com

Received: July 31, 2016 | Published: August 03, 2016

5. Pal R, Sagar V. Antecedent risk factors of xerophthalmia among Indian rural preschool children. Eye Contact Lens. 2008;34(2):106-108.

6. Kamruzzaman M, Hakim MA. Socio-economic Status of Child Beggars in Dhaka City. Journal of Social Sciences and Humanities. 2015;1(5):516-520.

7. Semba RD, de Pee S, Panagides D, et al. Risk factors for xerophthalmia among mothers and their children and for mother-child pairs with xerophthalmia in Cambodia. Arch Ophthalmol. 2004;122(4):517-523.

8. Rahman A, Hakim MA. Malnutrition Prevalence and Health Practices of Homeless Children: A Cross-Sectional Study in Bangladesh. Science Journal of Public Health. 2016;4(1-1):10-15.

9. Sherwin JC, Reacher MH, Dean WH, et al. Epidemiology of vitamin A deficiency and xerophthalmia in at-risk populations. Trans $R$ Soc Trop Med Hyg. 2012;106(4):205-214.

10. http://www.who.int/features/factfiles/blindness/blindness facts/en/ index6.html

11. Dary O, Mora JO. Food fortification to reduce vitamin A deficiency: International vitamin A consultative group recommendations. J Nutr. 2002;132(9):2927S-2933S.

12. Shrivastava SR, Shrivastava PS. Evaluation of trained accredited social health activist (ASHA) workers regarding their knowledge, attitude and practices about child health. Rural Remote Health. 2012;12(4):2099.

13. Arlappa N. Vitamin A Deficiency is Still a Public Health Problem in India. Indian Pediatr. 2011;48(11):853-854.

14. Hakim MA. Malnutrition Prevalence and Nutrition Counseling in Developing Countries: A Case Study. International Journal of Nursing and Health Science. 2016;3(3):19-22.

15. Rahman A. Significant Risk Factors for Childhood Malnutrition: Evidence from an Asian Developing Country. Science Journal of Public Health. 2016;4(1-1):16-27. 
16. Karmen A. Crime Victims: An Introduction to Victimology. Wardsworth Publishing; 1984:35-38.

17. Ending Malnutrition by 2020: an Agenda for Change in the Millennium. Final Report to the ACC/SCN by Commission on the Nutrition Challenges of the 21st Century. 2000.
18. Ghimire J. Malnutrition: Still Challenging in Nepal. J Nutr Health Food Engg. 2016;4(5):00145. 